\title{
A TWO-WAY RANDOMIZED CROSS-OVER PHARMACOKINETIC AND PHARMACODYNAMIC EVALUATION OF ADV6209, AN INNOVATIVE ORAL SOLUTION OF MIDAZOLAM
}

\author{
M. Brackhahn1, F. Marçon², C. Guittet ${ }^{3}$, M.A. Manso ${ }^{3}$, I. Burton ${ }^{4}$, L.A. Granier ${ }^{3}$ \\ ${ }^{1}$ Kinder- und Jugendkrankenhaus, Hannover, Germany, ${ }^{2} \mathrm{CHU}$ d'Amiens-Picardie, France, ${ }^{3}$ Advicenne Pharma, Nîmes, France, \\ ${ }^{4}$ ClinBay SPRL, Genappe, Belgium
}

\section{BACKGROUND AND GOAL OF THE STUDY}

One of the most widely used medications for moderate sedation in paediatric patients is oral midazolam. However, in most European countries oral midazolam is not licensed and off-label use is common. The forms used present very poor acceptability as major drawback, mainly due to their strong bitter taste.

An innovative $0.2 \%(\mathrm{w} / \mathrm{v})$ midazolam solution has been developed (Fig.1), based on the formation of midazolam-cyclodextrin inclusion complexes, which provides benefits that include bitterness masking, solubility and stability improvement [1].

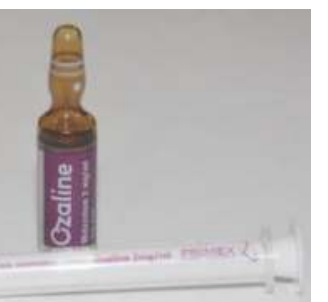

\section{Fig 1. Presentation of ADV6209 product}

This study aimed at evaluating the impact of cyclodextrins on the pharmacokinetcs (PK) and pharmacodynamics (PD) of oral midazolam) in adults, prior to the investigation of ADV6209 in paediatric patients.

\section{MATERIALS AND METHODS}

A Phase I $(n=12)$ randomized study with a standard two-way crossover design (15 mg ADV6209 orally - 5 mg Hypnovel® IV) was performed in healthy non-smoking adult subjects, aged 18 to 55 years, with a BMI $18.5-25 \mathrm{~kg} / \mathrm{m}^{2}$.

After single administration of ADV6209, blood samples were drawn just before and $5,10,15,20,30,40,50$ minutes and 1 , 1.5, 2, 4, 6, 9 and 12 hours after administration. Plasma concentrations of midazolam (MDZ) and its active metabolite, $\alpha$ hydroxymidazolam $(\alpha-\mathrm{OHM})$, were determined using a validated LC-MS/MS method.

The PK parameters for MDZ and $\alpha-\mathrm{OHM}$, including absolute oral bioavailability, were determined using a non-compartmental method.

The sedative effect was measured using a visual analog scale (VAS) for alertness [2] and the observer's assessment of alertness/sedation (OAA/S) scale [3] at different time points up to 12 hours after administration. Subjects with OAA/S score $\leq 17$ were considered as sedated.

Safety and tolerability were assessed. The subjects were physically examined and their vital signs were monitored. Routine laboratory tests were performed and adverse events were recorded.

\section{RESULTS AND DISCUSSION}

\section{Pharmacokinetics}

The PK profiles for MDZ and $\alpha-\mathrm{OHM}$ were as shown in Fig. 2 . The corresponding PK parameters are summarised in Table 1.

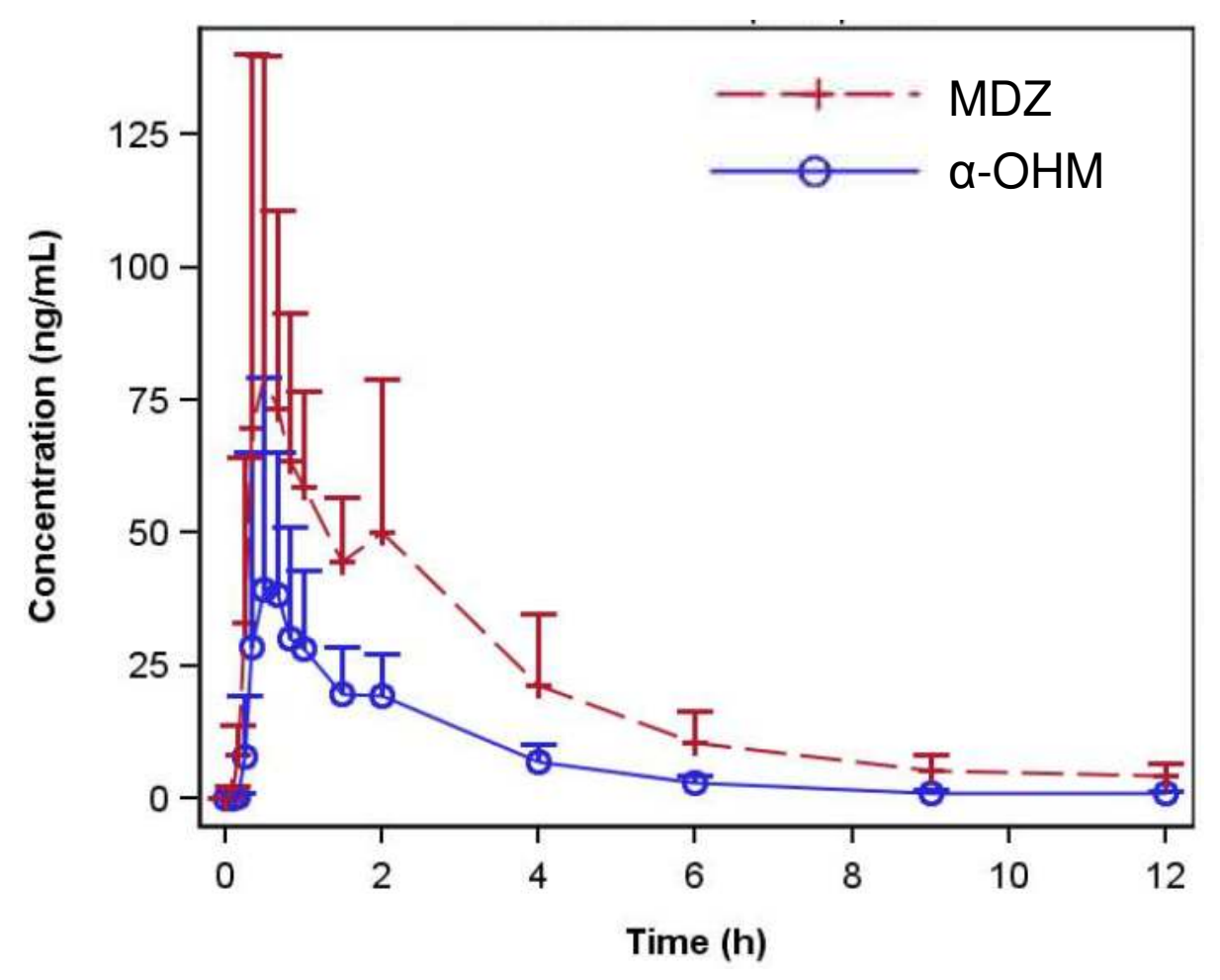

Fig 2. Mean (SD) MDZ and $\alpha$-OHM concentration-time profiles for ADV6209 (linear view)
Table 1. Summary of pharmacokinetic parameters for ADV6209 in adults. Mean (SD); Median (range) for Tmax

\begin{tabular}{|c|c|c|c|c|c|c|c|}
\hline & $\begin{array}{c}\mathrm{C}_{\max } \\
(\mathrm{ng} / \mathrm{mL})\end{array}$ & $\begin{array}{l}T_{\max } \\
\text { (h) }\end{array}$ & $\begin{array}{c}\mathrm{AUC}_{0-\mathrm{t}} \\
\left(\mathrm{h}^{*} \mathrm{ng} / \mathrm{mL}\right)\end{array}$ & $\begin{array}{c}A^{*} C_{0-\infty} \\
\left(h^{*} n g / m L\right)\end{array}$ & $\begin{array}{l}t_{1 / 2} \\
(h)\end{array}$ & $\begin{array}{c}\mathrm{Cl} / \mathrm{F} \\
(\mathrm{L} / \mathrm{min})\end{array}$ & $\begin{array}{c}\mathrm{Vz} / \mathrm{F} \\
\text { (L) }\end{array}$ \\
\hline MDZ & & & & & & & \\
\hline & & & & & $(0.245)$ & & \\
\hline
\end{tabular}

Oral bioavailability with ADV6209 was $39.4 \%$ (16.3 to $52.4 \%$ ), in close agreement with literature values for other oral midazolam forms. The metabolic ratio was significantly higher for ADV6209 than for Hypnovel $\AA$ ( 0.387 and 0.134 , respectively), which could be explained by the important pre-systemic metabolism of the drug administered by the oral route. The contribution of $\alpha-\mathrm{OHM}$ to the effect is therefore greater by the oral than by the IV route.

\section{Pharmacodynamics}

Overall, ADV6209 provided sedation (OAA/S score $\leq 17)$ within 30 minutes and over at least 2 hours and PD scores reflected well the extent of sedation/alertness in relation with midazolam plasma concentrations, as shown in Fig. 3.

Sedation was also observed with the VAS, as a change from baseline of at least $40 \mathrm{~mm}$ (on a $100 \mathrm{~mm}$ VAS) from $0.50 \mathrm{~h}$ to $1.50 \mathrm{~h}$ after ADV6209 administration. After 4 hours post-dose, the sedative effects had totally disappeared.

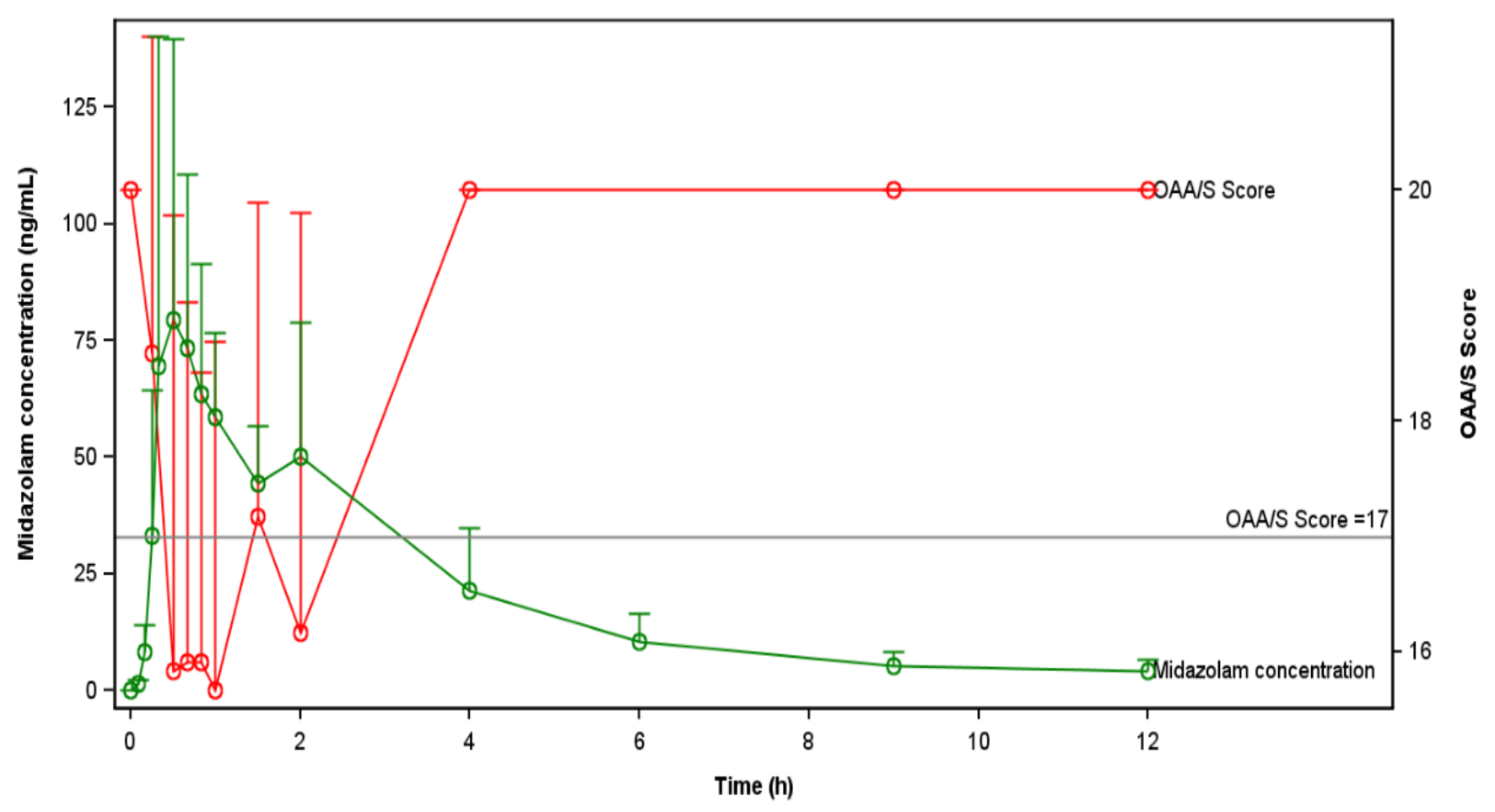

Fig 3. Mean midazolam plasma concentration and OAA/S score profiles after single administration of ADV6209 in adults

The minimum plasma concentration required to reach a sedative effect $\left(C_{\min }\right)$ was $53.05 \mathrm{ng} / \mathrm{mL}(95 \% \mathrm{Cl}, 46.65,60.44)$, in agreement with the literature from investigation of other oral midazolam formulations in adults.

\section{Discussion}

Midazolam complexation with cyclodextrins in order to obtain a solution with improved pharmaceutical characteristics and palatability did not appear to alter PK and PD parameters. Safety and tolerability were also very good.

\section{CONCLUSION}

Results in adults indicated that significant modifications of PK and PD parameters would be unlikely in children administered ADV6209, and supported further evaluation of this innovative product for moderate sedation in the paediatric population.

\section{REFERENCES}

[1] Marçon et al. (2009) Int. J. Pharm. 379:244-50

[2] Bond and Lader (1974) Br. J. Med. Psychol. 47:211-18

[3] Chernik et al. (1990) J. Clin. Psychopharmacol.10:244-51 